\title{
Picomolar inhibition of SARS-CoV-2 variants of concern by an engineered ACE2-IgG4-Fc fusion protein
}

\section{Hristo Svilenov}

Department of Chemistry, Technical University of Munich

\section{Julia Sacherl}

School of Medicine, Technical University of Munich / Helmholtz Zentrum München

\section{Alwin Reiter}

Formycon AG

\section{Lisa Wolff}

School of Medicine, Technical University of Munich / Helmholtz Zentrum München

\section{Cho-Chin Cheng}

School of Medicine, Technical University of Munich / Helmholtz Zentrum München

\section{Marcel Stern}

Max von Pettenkofer Institute \& Gene Center, Virology, LMU München https://orcid.org/0000-0002-

7692-6905

\section{Vincent Grass}

Technical University of Munich https://orcid.org/0000-0001-7710-4789

\section{Frank-Peter Wachs}

Formycon AG

Nicole Simonavicius

Formycon AG

\section{Susanne Pippig}

Formycon AG

\section{Florian Wolschin}

Formycon AG

\section{Oliver Keppler}

LMU Muenchen https://orcid.org/0000-0002-1384-8946

\section{Johannes Buchner}

Technical University Munich https://orcid.org/0000-0003-1282-7737

\section{Carsten Brockmeyer ( $\sim$ Carsten.Brockmeyer@formycon.com )}

Formycon AG

\section{Ulrike Protzer ( $\nabla$ protzer@tum.de )}


School of Medicine, Technical University of Munich / Helmholtz Zentrum München https://orcid.org/0000-0002-9421-1911

\section{Article}

Keywords: SARS-CoV-2, engineered ACE2-IgG4-Fc fusion proteins, picomolar inhibition

Posted Date: May 14th, 2021

DOI: https://doi.org/10.21203/rs.3.rs-459941/v1

License: (9) This work is licensed under a Creative Commons Attribution 4.0 International License. Read Full License

Version of Record: A version of this preprint was published at Antiviral Research on November 1st, 2021. See the published version at https://doi.org/10.1016/j.antiviral.2021.105197. 


\section{Abstract}

SARS-CoV-2 enters host cells after binding through its spike glycoprotein to the angiotensin-converting enzyme 2 (ACE2) receptor. Soluble ACE2 ectodomains bind and neutralize the virus, yet their short in vivo half-live limits their therapeutic use. This limitation can be overcome by fusing the fragment crystallizable (Fc) part of human immunoglobulin $\mathrm{G}(\mathrm{IgG})$ to the ACE2 ectodomain, but this bears the risk of unwanted Fc-receptor activation and antibody-dependent disease enhancement. Here, we describe optimized ACE2IgG4-Fc fusion constructs that avoid Fc-receptor activation, preserve the desired ACE-2 enzymatic activity and show promising pharmaceutical properties. The engineered ACE2-IgG4-Fc fusion proteins neutralize the original SARS-CoV, pandemic SARS-CoV-2 as well as the rapidly spreading SARS-CoV-2 variants-ofconcern, B.1.17 and B.1.351. Importantly, these variants-of-concern are inhibited at picomolar concentrations proving that ACE-2-IgG4 maintains - in contrast to therapeutic antibodies - its full antiviral potential. Thus, ACE2-IgG4-Fc fusion proteins are promising candidate anti-antivirals to combat the current and future pandemics.

\section{Main Text}

Angiotensin-converting enzyme 2 (ACE2) serves as a common entry receptor for the human coronavirus (CoV)-NL63, the original SARS-CoV from 2003 and the novel, pandemic SARS-CoV-2 into their host cells by binding the spike protein on the virus surface ${ }^{1-3}$. Membrane fusion of SARS-CoV-2 is enabled by proteolytic activation of the spike protein by cell surface protease TMPRSS2 ${ }^{2}$. Neuropilin- 1 has recently been identified to bind a furin-cleaved spike protein handing the virus over to ACE2. ${ }^{4}$ ACE2 is expressed on the plasma membrane of epithelial cells in the respiratory tract and lung $^{3}$, but also in other tissues like intestine, testes, liver, kidney, brain, and in the cardiovascular system. ${ }^{5-7}$

ACE2 is an 805 amino acid type-l transmembrane protein consisting of extracellular, transmembrane and cytosolic domains. ${ }^{8}$ The extracellular domain is a zinc metalloprotease, which enzymatically functions as a carboxypeptidase ${ }^{9,10}$ suppressing the renin-angiotensin-aldosterone system (RAAS) by cleaving angiotensin II into heptapeptide angiotensin-(1-7) and cleaving other vasoactive peptides. ${ }^{11,12}$ Angiotensin-(1-7) lowers the diastolic blood pressure, has anti-inflammatory, anti-proliferative and antifibrotic effects ${ }^{13}$ and thereby protects lung, heart, kidney and other organs from injury. ${ }^{5-7}$ The potential contribution of angiotensin II to the COVID-19 pathophysiology has been indicated by reports that angiotensin II levels in plasma samples from COVID-19 patients were markedly elevated and correlated with viral load and severity of the disease. ${ }^{14,15}$

ACE2-Fc fusion proteins, composed of an IgG Fc domain fused to the extracellular domain of ACE2, have been suggested as a high-priority treatment option for COVID-19. ${ }^{16,17}$ In addition to neutralizing SARSCOV and SARS-CoV-2, the ACE2's enzymatic activity affecting the RAAS provides a second mode of action, potentially alleviating the pathophysiology of acute respiratory distress syndrome. Therapeutic use of a soluble human recombinant ACE2 dimer (APN01) with a half-life of 10 hours is currently 
investigated in patients with COVID-19. ${ }^{18-20}$ Strong in vitro SARS-CoV-2 neutralizing activity has been described for sequence variants of ACE2-IgG1-Fc fusion proteins ${ }^{21-26}$, and ACE2-IgG1-Fc (HLX71) has entered phase 1 clinical studies. ${ }^{27}$

A concern arising from the experience with vaccines and neutralizing antibodies is antibody-mediated enhancement (ADE) of infection, or disease-mimicking pathophysiology by Fc-effector functions such as complement and antibody-dependent cell cytotoxicity. ${ }^{28}$ Moreover, binding of Fc receptor gamma III (CD16) has led to infection of CD16 positive cells by Middle East respiratory syndrome (MERS)-CoV. ${ }^{29,} 30$ While IgG1-Fc strongly binds to CD16 and inducing pronounced cytotoxicity, Fc-related effector functions are minimal for IgG4-Fc. ${ }^{31}$ In this regard, the IgG4-Fc fragment appears a preferred fusion partner for ACE2. However, it is well known that naturally occurring IgG4 antibodies are less stable than IgG1 variants due to the formation of half antibodies, which limits their use in pharmaceutical preparations. ${ }^{32-}$ ${ }^{35}$ To generate a stable ACE2-IgG4-Fc fusion protein, we have therefore chosen the immunoglobulin Fc region of an IgG4/kappa isotype with an S228P sequence alteration in the hinge region. ${ }^{33}$ For the ACE2 domain, two different truncations (Q18-G732 and Q18-S740) were used, and point mutations were introduced in the ACE2 domain to abrogate its enzymatic activity.

Here we show that an ACE2-IgG4-Fc fusion protein does not only have favorable pharmaceutical features but also efficiently neutralizes the 2003 SARS-CoV as well as circulating strains of SARS-CoV-2, including the variants of concern (VoC), B.1.17 and B.1.351.

\section{Results}

\section{Engineering, expression and purification of ACE2-Fc proteins}

First, we wanted to create ACE2-Fc molecules with different biological properties using the PyMOL Molecular Graphics System (version 2.3.3., Schrödinger, LLC., 2020). ACE2-IgG4-Fc and ACE2-IgG1-Fc fusion proteins were designed based on crystal and EM structures of the ACE2 extracellular domain, the SARS-CoV-2 spike (S) protein and its receptor-binding domain (RBD), as well as the IgG4-Fc and IgG1-Fc domains (Figure 1a and b). ${ }^{3,36-38}$ Details of the ACE2 sequences fused to the Fc fragments of IgG4 and $\lg \mathrm{G} 1$ are shown in Figure 1c.

The expression yields of all constructs were in a similar range, although slightly higher for Q18-G732 ACE2-Fc fusion proteins (Supplementary Table 1). The purity of the ACE2-Fc fusion proteins under investigation ranged between $95 \%$ and $98 \%$, as evident from capillary electrophoresis sodium dodecyl sulfate (CE-SDS) and size exclusion chromatography (SEC) analysis (Supplementary Table 1). High molecular weight fractions (HMWS) measured after purification were slightly lower for Q18-G732 ACE2Fc fusion proteins (Supplementary Table 1). Peptide mapping confirmed the presence of the modifications in the ACE2-Fc fusion proteins. 


\section{Variations in the ACE2-Fc sequences allow preserving structural properties and engineering enzymatic activity of ACE2}

To study the secondary structure to the ACE2-Fc fusion construct, we used protein circular dichroism (CD). The Far-UV (200-260 nm) CD spectra of the fusion proteins could be superimposed indicating that the secondary structures are preserved among all constructs, regardless of the sequence variations (Figure 2a). The same held true for the Near-UV $(250-350 \mathrm{~nm})$ CD spectra, which indicated that the overall tertiary structure is also highly similar in all ACE2-Fc proteins investigated (Figure 2a).

Size-exclusion chromatography coupled to multi-angle light scattering (SEC-MALS) was used to investigate the oligomeric state of the fusion proteins. All ACE2-Fc fusion molecules tested exhibit similar elution times and molecular masses of 230 to $235 \mathrm{kDa}$ (Figure $2 \mathrm{~b}$ ). These values agreed well with the theoretical mass of a homodimer, which is $216-218 \mathrm{kDa}$ based on calculations from the primary sequence. The slightly higher molecular mass measured in solution was due to the glycosylation of the proteins. Reducing and non-reducing sodium dodecyl sulfate-polyacrylamide gel electrophoresis (SDSPAGE) (Figure $2 \mathrm{c}$ ) revealed that all ACE2-Fc fusion proteins analyzed under reducing conditions with dithiothreitol (DTT) run at about 110-120 kDa, which correlated to the theoretical mass of a monomeric ACE2-Fc molecule. The non-reduced ACE2-Fc fusion proteins exhibited a much higher apparent molecular weight, indicating that the intermolecular disulfide bonds in the ACE2-Fc homodimers are formed, which agrees with results from capillary electrophoresis sodium dodecyl sulfate (CE-SDS) under reducing and non-reducing conditions.

The enzymatic activity of the engineered ACE2-Fc fusions was evaluated by their ability to cleave synthetic ACE2 substrate peptidyl-4-methylcoumaryl-7-amide (MCA), releasing a fluorescent product. All ACE2-Fc constructs with wildtype (WT) ACE2 sequences cleave the same amount of MCA during a 30min incubation period, while mutations in the active ACE2 site resulted in a complete loss of enzymatic activity (Figure $\mathbf{2 d}$ and $\mathrm{e}$ ).

\section{ACE2-Fc fusion constructs strongly interact with the receptor-binding domain (RBD) of SARS-CoV-2}

Surface plasmon resonance (SPR) allowed us to determine the binding affinity of our ACE2-Fc constructs to the RBD of the spike protein of SARS-CoV-2 that was recombinantly expressed and immobilized. The ACE2-Fc fusion proteins bound in a concentration-dependent manner to the viral protein domain, while an unrelated Fc fusion protein (aflibercept) used as a control showed no interaction with the ligand (Figure 3a). The binding constants revealed that all constructs analyzed bind to the immobilized SARS-CoV-2 RBD with an equilibrium dissociation constant $\left(K_{D}\right)$ of around $4 \mathrm{nM}$ (Figure $3 \mathrm{~b}$ ). This indicated that the structural variations do not influence the interaction between the ACE2-Fc fusion proteins and the RBD of SARS-CoV-2.

Neutralizing activities of the ACE2-Fc fusion proteins against the SARS-CoV-2 spike protein were tested in a competition enzyme-linked immunoassay (ELISA). All ACE2-Fc constructs tested potently inhibited the binding of spike S1 protein of SARS-CoV-2 to ACE2 (Figure 3c). Consistent with their affinities to the 
SARS-CoV-2 RBD, there were no significant differences between the different fusion proteins. The halfmaximal inhibitory concentrations (IC50 values) for the SARS-CoV-2 spike S1 protein ranged from 2.5 to $3.5 \mathrm{nM}$.

\section{Effect of the Fc part on ACE2-IgG-Fc binding to FcgRI, FcgRIIla and FCRn}

The Fc-part can be important for the interaction of the molecules with Fc-receptors. We therefore used SPR to test the interaction of two ACE2-IgG4-Fc and two ACE2-IgG1-Fc proteins with FcgRI and FcgRIlla. The ACE2-IgG4-Fc fusion proteins showed slightly lower affinity to FcgRI when compared to the IgG1 counterparts (Table 1). The ACE2-IgG4-Fc showed no binding to FcgRIlla, which contrasts with the ACE2IgG1-Fc molecules (Table 1).

IgG half-life is primarily regulated by binding to the neonatal Fc Receptor, FcRn, through the IgG's constant region, Fc. Therefore, we were interested in whether the ACE2-IgG-Fc constructs still bind to FcRn and used SPR to test the binding of two ACE2-IgG4-Fc and two ACE2-IgG1-Fc proteins to FcRn. All four constructs had similar affinity to the FcRn (Table 1) indicating that usage of the IgG4 Fc domain allows to preserve in vivo half-life.

Table 1. Binding affinities of ACE2-FC constructs to FC-receptors

\begin{tabular}{|c|c|c|c|}
\hline Construct & FcgRI & FcgRIIIa & FcRn \\
\cline { 2 - 4 } & $\mathrm{K}_{\mathrm{D}}(\mathrm{nM})$ & $\mathrm{K}_{\mathrm{D}}(\mu \mathrm{M})$ & $\mathrm{K}_{\mathrm{D}}(\boldsymbol{\mu M})$ \\
\hline 1 & $45 \pm 0.2$ & No binding & $2.9 \pm 0.68$ \\
\hline 3 & $43 \pm 5.2$ & No binding & $3.9 \pm 0.62$ \\
\hline 5 & $10 \pm 2.2$ & $0.6 \pm 0.45$ & $3.4 \pm 0.05$ \\
\hline 7 & $11 \pm 0.8$ & $0.8 \pm 0.54$ & $3.5 \pm 0.62$ \\
\hline
\end{tabular}

Mean \pm SD of duplicate measurements.

\section{Neutralization of SARS-COV-2-GFP by ACE2-IgG4-FC}

We next wanted to test whether the competition of our ACE2-Fc fusion constructs with binding of the SARS-CoV-2 via S1 to its receptor ACE2 translates into neutralization of infectious virus. Because of the expected favorable in vivo characteristics, we chose two IgG4-based ACE2-Fc fusion proteins, construct 1 and construct 3 , for virus neutralization tested by live-cell imaging using the IncuCyte S3 platform in a biosafety level 3 laboratory. When Vero E6 cells were infected with SARS-CoV-2-GFP ${ }^{39}$ pre-incubated with serial dilutions of the two ACE2-IgG4-Fc fusion proteins (ACE2 Q18-G732 wildtype and ACE2 Q18-G732 $\mathrm{H} 374 \mathrm{~N} / \mathrm{H} 378 \mathrm{~N}$ fused to IgG4-Fc S228P) the virus was neutralized in a concentration-dependent manner 
and no green fluorescent protein (GFP) expression was detected in contrast to cell layers showing increasing GFP expression when infected with the non-treated virus. (Figure 4a and Supplementary Movies). This demonstrates that construct 1 and construct 3 effectively inhibit SARS-CoV-2-GFP infection in vitro.

\section{Efficient neutralization of primary SARS-CoV-2 isolates including major variants of concern}

To determine whether the ACE2-Fc constructs neutralize different isolates of SARS-CoV-2, we compared the neutralization capacity of each of the eight ACE2-Fc fusion constructs against a range of primary isolates from patients. Hereby, we also included the original SARS-CoV isolate from $2003^{40}$ as well as two different SARS-CoV-2 strains isolated from patients in January and April 2020 carrying the D614G mutation in the viral spike protein. First, all eight ACE2-IgG-Fc fusion proteins developed against the pandemic SARS-CoV-2 also neutralized the first human pathogenic SARS-CoV circulating in $2003^{40}$ with $50 \%$ inhibitory concentration (IC50 values) in the range of 90-250 nM (Figure 4b)

Second, to test the ACE2-Fc constructs for their ability to neutralize SARS-CoV-2, we evaluated the antiviral activity against SARS-CoV-2-Jan isolated from the earliest documented COVID-19 patient in Germany ${ }^{41,42}$, which was directly connected to the initial outbreak in Wuhan, China. All ACE2-Fc fusion proteins displayed strong neutralizing potential against SARS-CoV-2-Jan (Figure 4b) with IC50 values in the range of 7-11 $\mathrm{nM}$.

Third, the ACE2-Fc fusion protein variants were also compared for their ability to neutralize a second SARS-CoV-2 isolate, SARS-CoV-2-April, which was isolated when the virus was massively spreading in Europe. SARS-CoV-2-April displayed a different plaque-forming phenotype than SARS-CoV-2-Jan (Supplementary Figure 1). All ACE2-Fc constructs displayed significantly increased neutralizing potential against SARS-CoV-2-April (Figure 4b) with IC50 in the picomolar range. The comparison of IC50 values showed an increasing neutralizing potential of ACE2-Fc fusion proteins, the more the SARS coronavirus evolved to allow for more efficient spread in the community.

\section{Increasing antiviral potential of ACE2-IgG4-Fc against emerging SARS-COV-2 variants of concern}

To determine whether the ACE2-Fc fusion proteins can prevent cell toxicity resulting from infection with SARS-CoV-2 VoC, we analyzed the cell viability of human alveolar basal epithelium-derived A549-hACE2 cells which were challenged with the different ACE2-Fc fusion protein-pre-treated VoCs. Because of their expected favorable in vivo features, we chose the two IgG4-based ACE2-Fc fusion proteins, construct 1 and construct 3 (Figure 5). Both ACE2-IgG4-Fc constructs entirely prevented SARS-CoV-2-induced cytotoxicity and, therefore, potently neutralized SARS-CoV-2-Jan (Figure 5) and SARS-CoV-2-April (Figure 5) with IC50 values in the range of 1-7 nM confirming previous results (Figure 4b). 
In addition, ACE2-IgG4-Fc constructs neutralized the SARS-CoV-2 VoC B.1.1.7 showing significantly increased neutralizing potential in comparison to SARS-CoV-2-Jan and April reaching IC50 values in the picomolar range (Figure 5, second lowest panel). Excitingly, ACE2-IgG4-Fc fusion constructs displayed an even higher antiviral potential against the SARS-CoV-2 VoC B.1.351, which is known to exhibit the strongest immune escape potential of all SARS-CoV-2 strains known so far (Figure 5, lowest panel) and also proved resistant to neutralization by an anti-RBD monoclonal antibody in our experiments (Supplementary Figure 2).

Taken together, ACE2-IgG4-Fc constructs show an increasing capacity to neutralize SARS-CoV-2 with increasing adaptation of the virus to the human population including the major VoCs.

\section{Discussion}

In this study, we designed, expressed and evaluated different ACE2-Fc fusion proteins with favorable biochemical features and demonstrate that they elicit a broad antiviral activity in the nano-molar or even picomolar range against human pathogenic beta-coronaviruses including SARS-CoV-2 VoCs as well as the 2003 SARS-CoV. Importantly, the more the SARS-CoV-2 spike protein evolved and diversified in the pandemic, and the more problematic immune escape became, the more efficient these virus isolates were inhibited by our ACE2-Fc fusion proteins.

All ACE2-IgG4-Fc and ACE2-IgG1-Fc fusion proteins designed inhibited infection of Vero E6 cells with the original SARS-CoV from 2003 with IC50 values in the range of 90-250 nM. A SARS-CoV-2 isolate from January 2020, which was obtained from the earliest documented COVID-19 cases in Germany, and thus is closely related to the original Wuhan strain, ${ }^{41-43}$ was inhibited with IC50 values of around $10 \mathrm{nM}$. Infection by the SARS-CoV-2-April variant predominantly circulating worldwide was prevented even more efficiently. Most importantly, our ACE2-IgG4-Fc constructs prevented infection and cell toxicity of the most infectious SARS-CoV-2 variant known so far, the "British" B.1.1.17 strain, and the variant of highest concern world-wide, the "South African" B-1-351 variant reaching picomolar IC50. This demonstrates that, in contrast to therapeutic antibodies targeting the viral spice protein, the virus cannot escape neutralization by or ACE2-IgG4-Fc fusion construct.

Surveillance of SARS-CoV-2 variants emerging over time identified genomic regions with increasing genetic variation. ${ }^{56-58} \mathrm{~A}$ D614G substitution in the C-terminal region stabilizing the spike protein is associated with an improved ability of the virus to bind its receptor, ACE2, and rapidly became the most prevalent variant worldwide. ${ }^{59,60}$ Over time, novel and even more infectious SARS-CoV-2 strains emerged, the so-called "British" variant B.1.1.7 being the prime example. ${ }^{61}$ Our results indicate that both the ACE2IgG4-Fc fusion proteins and the ACE2-IGg1-Fc fusion proteins neutralize these pandemic SARS-CoV-2 variants even more potently than the early SARS-CoV-2, which originated from Wuhan. The lower efficacy against the original SARS-CoV from 2003 is in line with the fact that the affinity of the SARS-CoV-2 spike protein for ACE2 is significantly higher than the affinity of the SARS-CoV spike protein. ${ }^{3} \mathrm{It}$, however, also indicates, that the VoCs evolving because they can bind more efficiently to ACE2 and therefore become 
more infectious can be targeted with our ACE2-IgG4 fusion protein even more efficiently. This helps to prepare for new potentially pandemic viruses stemming from animal reservoirs, as it happened recently with "cluster 5", a SARS-CoV-2 variant with a combination of mutations still investigated for their impact on disease severity and resistance to vaccination and therapeutic antibodies. ${ }^{62,63}$

Our findings are highly relevant in the context of the emerging SARS-CoV-2 variants that at least partially escape neutralization by therapeutic antibodies. ${ }^{44,45}$ The use of one of the first antibodies used in COVID19 therapy, bamlanivimab, was even halted by the US-FDA only four months after it had gained authorization for emergency use. The FDA has is now recommending to develop and use antibodies only for combination therapies targeting different epitopes due to viral resistance concerns. ${ }^{46}$ However, it is probably only a matter of time until we see SARS-CoV-2 variants emerging that escape multiple therapeutic antibodies. Unlike antibodies, our ACE2-IgG4-Fc fusion protein will retain its potent virus neutralization efficiency as it is vital for the virus to retain its receptor binding capacity. Therefore, coronavirus variants that mutate to escape ACE2-Fc-binding will lose fitness and become less infectious.

In addition to the "British" B.1.17 VoC, the emergence of SARS-CoV-2 VoCs which are able to at least partially escape immunity raises additional concerns, namely those which carry a mutation of amino acid 484 such as the "South African" B.1.351, the "Brazilian" P1 and P2 variants and the most recent variants detected in India or California. B.1.1.7 has been shown to be refractory to neutralization by most monoclonal antibodies against the $\mathrm{N}$-terminal domain of the spike protein and is relatively resistant to a few monoclonal antibodies against the receptor-binding domain ${ }^{45}$ while it is still sensitive to plasma from individuals who have recovered from COVID-19 or sera from individuals who have been vaccinated against SARS-CoV-2. The B.1.351 variant is not only refractory to neutralization by most monoclonal antibodies directed against the $\mathrm{N}$-terminal domain of the spike protein but also by multiple individual monoclonal antibodies against the receptor-binding motif. In addition, the B.1.351 variant shows a worrisome escape from neutralization by convalescent plasma and sera from individuals who have been vaccinated. ${ }^{45,64}$ Our data strongly indicate that all these variants can still be targeted by the engineered ACE2-IgG4 fusion constructs.

ACE2 plays a central role in the homeostatic control of cardio-renal actions and has been shown to protect against severe acute lung injury and acute angiotensin II-induced hypertension. ${ }^{47,} 48 \mathrm{~A}$ soluble dimer (APN019) has been safely tested in a clinical phase I study in healthy volunteers and in a phase II study in patients with an acute respiratory distress syndrome. ${ }^{18,19}$ It is currently being tested for its therapeutic effect in a phase II study in COVID-19 patients. ${ }^{20}$ We used the full length ACE2 ectodomain sequence Q18-S740 and a shortened version comprising Q18-G732. Most importantly, binding to the SARS-CoV-2 viral spike protein to both variants was comparable with a $K_{D}$ of $4 \mathrm{nM}$.

Pharmacokinetic studies in mice and humans revealed that recombinant human ACE2 exhibits fast clearance rates resulting in a short half-life of only a few hours. ${ }^{18,20,47}$ When the extracellular domain of murine ACE2 was fused to an Fc fragment of murine immunoglobulin IgG the ACE2-Fc fusion protein 
demonstrated a prolonged in vivo half-life and effective organ protection in murine models of both, acute and chronic angiotensin II-dependent hypertension. ${ }^{49}$

ACE2-Fc fusion proteins are homodimers stabilized by disulfide bonds in the hinge region, similar to IgGs. ${ }^{50}$ Functional variants of ACE2-IgG1-Fc fusion proteins have been described in the literature ${ }^{21-26}$, and a first fusion protein designed with an IgG1 Fc portion to prolong the circulating half-life is currently in a phase I clinical study by Hengenix Biotech Inc. ${ }^{27}$ In our study, novel ACE2-Fc fusion proteins were designed in which the ACE2 domain is fused to the Fc fragment of human IgG4 (ACE2-IgG4-Fc) containing a stabilizing S228P mutation in the hinge region. Although ACE2 domain and the Fc part most likely fold independently, both Fc domains could be used to obtain stable fusion proteins and neither the interaction of ACE2 with the virus spike protein nor its enzymatic function was affected. Thus, engineering general features of the fusion protein is possible without interfering with spike protein interaction.

The presence of the Fc domain markedly increases the plasma half-life of ACE2-Fc due to the interaction of the Fc domain with the neonatal Fc-receptor (FcRn), and therefore a slower renal clearance of the fusion molecule. FcRn is broadly expressed on many cell types including endothelial cells and respiratory epithelial cells. ${ }^{51,52}$ Binding to FcRn extends the systemic half-life by chaperoning bound Fc fusion proteins away from lysosomal degradation. In addition, FcRn transports IgG and Fc fusion molecules across mucosal barriers into the lumen of the respiratory and intestinal tract thereby providing dynamic trafficking between circulating and luminal IgG molecules at mucosal sites. ${ }^{51,53}$ Here we showed that the ACE2-IgG4-Fc has preserved binding to FcRn with the same affinity as the ACE2-IgG1-Fc counterparts. On the other hand, the ACE2-IgG4-Fc did not bind to CD16 (FcgRIIla) in contrast to ACE2-IgG1-Fc, although the constant heavy chain regions of the different lgG subclasses share over $95 \%$ sequence homology. IgG4 in particular has poor ability to engage $\mathrm{C} 1 \mathrm{q}$ and Fc gamma receptors and has been associated with anti-inflammatory properties. ${ }^{54}$ This allowed us to reduce the risk of disease enhancement related to complement or antibody-dependent cytotoxicity and infection via CD16 Fc receptor ${ }^{31}$ and avoid antibodymediated disease progression of COVID-19 that has recently been reported. ${ }^{55}$ Most importantly, using our design, ACE2-IgG4-Fc fusion constructs show equally high binding affinity to the SARS-CoV-2 RBD and spike neutralizing the virus with IC50 values in the picomolar range.

The SARS-CoV-2 pandemic has caused an unprecedented challenge to develop COVID-19 therapies. However, progress with antiviral drugs has been slow. Here we show that ACE2-IgG4-Fc fusion proteins have favorable biophysical and pharmaceutical characteristics and significant in vitro SARS-CoV-2 neutralizing potency. The Fc part from IgG4 could bring clinical benefits for ACE2-Fc proteins by avoiding potential antibody-dependent disease enhancement during treatment. In addition, our data showed that ACE2-IgG4-Fc fusion proteins displayed increasing neutralizing potential, the further the SARS-CoV variant adapted to its human host becoming more infectious or escaping immune responses. For the currently emerging SARS-CoV-2 VoCs, alternative therapies are urgently needed, and ACE2-Fc fusion proteins certainly are interesting candidates. Thus, our ACE2-IgG4-Fc fusion protein is a promising 
candidate not only for therapeutic use in the current SARS-CoV-2 pandemic including more infectious SARS-CoV-2 VoC but also for future coronavirus infectious diseases.

\section{Materials And Methods}

\section{Construct design}

ACE2 amino acid sequence modifications were designed by computer-aided modelling. ACE2 ectodomains of different length, Q18-G732 and Q18-S740, with or without mutation of the catalytic site (wild type or $\mathrm{H} 374 \mathrm{~N} / \mathrm{H} 378 \mathrm{~N}$ mutant) ${ }^{65}$ were combined with the Fc fragment of IgG4 bearing a stabilizing S228P mutation in the hinge region. ${ }^{33}$ For comparison, the same ACE2 sequence variants were fused to the Fc fragment of IgG1 with a truncated hinge region (DKTHTCPPCPA).

\section{Generation of expression plasmids}

Plasmids encoding the Fc fusion proteins were generated at ThermoFisher. Genes of interest were subcloned into pcDNA3.1 Zeocin expression plasmids (Invitrogen V860-20) with an elongated CMV promoter using Hindlll/Xhol restriction sites. Following amplification in Escherichia coli, expression plasmids were isolated and analyzed by restriction analysis as well as DNA sequencing.

\section{Protein expression}

Using the FreeStyle 293 Expression System (ThermoFisher), the different ACE2-Fc fusion proteins were transiently expressed in $3 \times 240 \mathrm{~mL}$ culture media. On day six, samples were analyzed for cell viability as well as cell density and supernatants were harvested by centrifugation followed by sterile filtration. ${ }^{66}$ The material was either stored at $-80^{\circ} \mathrm{C}$ until purification or subjected directly to purification. Small samples were taken from the pools to determine expression yields by bio-layer interferometry (BLI).

\section{Protein purification}

Purification of the fusion proteins secreted into the culture medium was performed by protein A column chromatography followed by preparative Size Exclusion Chromatography (SEC). For protein A purification, after loading the sample, the Amsphere A3 column (JSR Life Sciences) was washed and the ACE2-Fc fusion proteins were eluted using $40 \mathrm{mM} \mathrm{NaAc}$, pH 3.0. Following elution, samples were first neutralized to $\mathrm{pH} 7.5$ using $1 \mathrm{M}$ Tris, $\mathrm{pH}$ 9.0, subsequently diluted 1:1 with $50 \mathrm{mM}$ Tris, $\mathrm{pH} 7.5,300 \mathrm{mM}$ $\mathrm{NaCl}$ and concentrated to $10 \mathrm{mg} / \mathrm{mL}$ using spin filters. Concentrated proteins were further purified with a Superdex 200 increase (GE Healthcare) column equilibrated with $50 \mathrm{mM}$ Tris, pH 7.5, $150 \mathrm{mM} \mathrm{NaCl}$. The main peak was pooled, the protein concentration was determined by slope spectrometry ${ }^{67}$ and adjusted to $1 \mathrm{mg} / \mathrm{mL}$. The protein solution was passed through a sterilizing filter and stored at $4^{\circ} \mathrm{C}$ until further usage.

Size exclusion chromatography with multi-angle light scattering_(SEC-MALS) 
A Shimadzu HPLC system with two concentration detectors (UV and refractive index) and a HELEOS II MALS detector were used for the measurements. The flow rate was $1 \mathrm{~mL} / \mathrm{min}$ and the running buffer was $50 \mathrm{mM}$ Tris, pH 7.5 and $150 \mathrm{mM} \mathrm{NaCl} .50 \mu \mathrm{g}$ of protein was injected on a Superdex 200 Increase 10/300 GL column (Cytiva). The chromatograms were evaluated with the Astra software.

\section{Circular dichroism $(\underline{\mathrm{CD}})$}

All CD measurements were performed with a Jasco J-1500 spectropolarimeter at $20^{\circ} \mathrm{C}$. The sample buffer consisted of $50 \mathrm{mM}$ Tris, pH 7.5 and $150 \mathrm{mM} \mathrm{NaCl}$. The Far-UV CD spectra were obtained in a $1 \mathrm{~mm}$ quartz cuvette using a protein concentration of $0.1 \mathrm{mg} / \mathrm{mL}$. The Near-UV CD spectra were measured in a $5 \mathrm{~mm}$ quartz cuvette using a protein concentration of $1 \mathrm{mg} / \mathrm{mL}$.

\section{ACE2 activity assay.}

An ACE2 activity assay kit from Abcam (Cat.No. ab273297) was used to measure the enzymatic activity of the constructs. The assay was performed according to the manufacturer's manual and is based on a synthetic peptidyl-4-methylcoumaryl-7-amide (MCA) that is cleaved by the ACE2 enzyme. Upon cleavage, free MCA is detected fluorometrically (Ex320nm/Em420nm) and quantified with a standard curve obtained with MCA standard solutions with known concentrations. Two commercially available ACE2-Fc proteins obtained from Genscript (Cat.No. Z03484-1) and Acrobiosystems (Cat.No. AC2-H5257) were used as reference.

\section{Determination of binding affinity to spike protein RBD using surface plasmon resonance}

The measurements were performed with a Biacore X-100 system and the Biotin CAPture kit (Cytiva). The running buffer was HBS-EP+ pH 7.4 (Cytiva). The ligand SARS-CoV-2 RBD with an AviTag (Acrobiosystems) was captured on the streptavidin chip to around $100 \mathrm{RU}$. Increasing concentrations of the analyte ACE2-Fc $(0.32,1.6,8,40$ and $200 \mathrm{nM})$ were injected over the immobilized ligand in a singlecycle kinetic mode. The obtained sensorgrams were evaluated with the Biacore X-100 software to obtain a binding constant $\left(\mathrm{K}_{\mathrm{D}}\right)$.

Determination of binding_affinity to Fc-receptors using surface plasmon resonance

A Biacore T200 was used for the Fc-receptor binding studies. For the FcgRI and the FcgRIlla experiments, the his-tagged FcgRI and FcgRllla with a concentration of $1.5 \mathrm{nM}$ were captured by injection of the solutions for $90 \mathrm{~s}$ with a flow rate of $5 \mu \mathrm{L} / \mathrm{min}$ over a covalently immobilized anti-his tag antibody on a CM5 chip. The running buffer was HBS-EP+ pH 7.4 (Cytiva). Five different concentrations of the ACE2-Fcs were injected in a single-cycle kinetic mode (3.7-300 nM for the experiment with FcgRI and 25-2000 nM for FcgRIIla). The FcgRI-binding data was fit to a heterogeneous ligand model and the first binding constant was reported. The FcgRIlla-binding data was fit to a two-state reaction model to derive the binding constant. For the FcRn experiments, the FcRn was covalently immobilized on a CM5 chip to around $50 \mathrm{RU}$. The sample buffer was HBS-EP+ pH 6.0 (Cytiva). The ACE2-Fcs were injected in five 
different concentrations from 205 to $8000 \mathrm{nM}$ in a single-cycle kinetic mode. The FcRn binding was evaluated with a steady-state affinity fit.

\section{SARS-CoV-2 Spike S1 Inhibition ELISA}

Inhibition of binding of SARS-CoV-2 spike S1 protein to ACE2 was tested using the ACE2:SARS-CoV-2 Spike S1 Inhibitor Screening Assay Kit (BPS Bioscience; Cat.No. 79945) according to the manufacturer's instructions with an adapted neutralization procedure. Briefly, biotinylated SARS-CoV-2 Spike S1 protein $(25 \mathrm{nM})$ was incubated with serial dilutions of the ACE2-Fc fusion proteins in a 96-well neutralization plate at room temperature (RT) for one hour with slow shaking (= neutralization mix).

ACE2 protein was added to a nickel-coated 96-well plate at a concentration of $1 \mu \mathrm{g} / \mathrm{mL}$ and incubated at RT for one hour with slow shaking. Following a washing step to remove unbound ACE2, the plates were blocked at RT for 10 min with slow shaking. Subsequently, the neutralization mix was transferred to the ACE2 coated plate and the plate was incubated at RT for one hour with slow shaking. Following a 10 min blocking step, the plate was incubated with Streptavidin-HRP at RT for one hour with slow shaking. Following a washing and a 10 min blocking step, the HRP substrate was added and the plate was analyzed on a chemiluminescence reader.

\section{Virus strains}

SARS-CoV-2-GFP (kindly provided by Volker Thiel, University of Bern, Switzerland) is based on the original Wuhan SARS-CoV-2 isolate (GenBank accession MT108784) and was reconstituted from a synthetic construct derived from SARS-2 BetaCoV/Wuhan/IVDC-HB-01/2019. ${ }^{39}$

SARS-CoV-2-Jan (SARS-CoV-2-Munich-TUM-1; EPI_ISL_582134), SARS-CoV-2-April (SARS-CoV-2 D614G; EPI_ISL_466888), SARS-CoV-2-B.1.1.7 (EPI_ISL_755639) and SARS-CoV (AY291315.1) were isolated from patient material in Germany. Briefly, SARS-CoV-2-Jan was isolated from a COVID-19 infected patient who was infected during the earliest documented COVID-19 outbreak in Germany at the end of January 2020 with a virus imported from Wuhan via a single contact in Shanghai. ${ }^{43}$ SARS-CoV-2-April was isolated during the first eminent wave of the pandemic in Europe in April 2020 from a patient in Munich, Germany. Both virus isolates as well as a control isolate from the early "Webasto" cluster outbreak ${ }^{68}$ contain the S1 D614G mutation showing significantly higher infectious titers in vitro. ${ }^{59}$

SARS-CoV-2-Jan, SARS-CoV-2-B.1.1.7, SARS-CoV and SARS-CoV-2-GFP ${ }^{39}$ were propagated and passaged in Vero E6 cells (derived from African green monkey kidney epithelial cells). SARS-CoV-2-April was isolated on Caco-2 cells followed by passaging in Vero E6 cells. All strains were cultured in DMEM medium ( $5 \%$ fetal calf serum (FCS), $1 \%$ penicillin/streptomycin (P/S), 200 mmol/L L-glutamine, 1\% MEMNon-Essential Amino Acids (NEAA), $1 \%$ sodium pyruvate (all from Gibco). Viral titer was determined by Plaque Assay. ${ }^{69}$

Plaque Assay. 
Viral titers were determined as described by Baer et al. ${ }^{69}$ with some modifications. Briefly, HepG2 or Vero E6 cells were plated in a 12-well plate at 5E05 cells/well in DMEM medium (Gibco) supplemented with $5 \%$ FCS, 1\% P/S, 200 mmol/L L-glutamine, 1\% MEM-NEAA, 1\% sodium-pyruvate (all from Gibco) and incubated overnight at $37^{\circ} \mathrm{C}$ and $5 \% \mathrm{CO}_{2}$. Cells were infected with serial dilution of virus sample in cell culture medium at $37^{\circ} \mathrm{C}$ for one hour. After discarding the supernatant, $1 \mathrm{~mL}$ of $5 \%$ carboxymethylcellulose (Sigma) diluted in Minimum Essential Media (Gibco) was added per well and the plate was incubated at $37^{\circ} \mathrm{C}$ until obvious plaques appeared. After removing the supernatant, cells were fixed with $10 \%$ paraformaldehyde (ChemCruz) at RT for 30 min. Next, a washing step with PBS was performed, followed by the addition of $1 \%$ crystal violet (Sigma; diluted in $20 \%$ methanol and water). Following an incubation time of $15 \mathrm{~min}$ at RT, the solution was washed away with PBS and the plate was dried. The viral titer (PFU/mL) of the sample was determined by counting the average number of plaques for a dilution and the inverse of the total dilution factor.

In vivo infection assay using SARS-CoV-2-GFP

Vero-E6 cells were plated in a 96-well plate at 1.4E04 cells/well in DMEM medium (Gibco) supplemented with $5 \% \mathrm{FCS}, 1 \% \mathrm{P} / \mathrm{S}, 200 \mathrm{mmol} / \mathrm{L}$ L-glutamine, 1\% MEM-NEAA, 1\% sodium-pyruvate (all from Gibco) and incubated overnight at $37^{\circ} \mathrm{C}$ and $5 \% \mathrm{CO}_{2}$. Serial dilutions of ACE2-Fc fusion proteins and SARS-CoV-2GFP were mixed in fresh media and pre-incubated at $37^{\circ} \mathrm{C}$ for one hour. Afterwards, Vero E6 cells were infected with the neutralized virus solution at a multiplicity of infection (MOI) of 0.6 infectious viruses per cell at $37^{\circ} \mathrm{C}$. After one hour, the neutralization mix was replaced by cell culture medium. Plates were placed in the IncuCyte S3 Live-Cell Analysis System (Essen BioScience, Newark, UK) and real-time images of uninfected mock cells (Phase channel) and infected (GFP and Phase channel) cells were captured every four hours for 72 hours. Virus control cells were infected with the same virus stock but without prior incubation with the ACE2-Fc fusion constructs using the identical protocol.

\section{Viral neutralization assay}

Vero E6 cells were plated in a 96-well plate at 1.6E04 cells/well in DMEM medium (Gibco) supplemented with $5 \% \mathrm{FCS}, 1 \% \mathrm{P} / \mathrm{S}, 200 \mathrm{mmol} / \mathrm{L}$ L-glumatine, 1\% MEM-NEAA, 1\% sodium-pyruvate (all from Gibco) and incubated overnight at $37^{\circ} \mathrm{C}$ and $5 \% \mathrm{CO}_{2}$. Serial dilutions of the ACE2-Fc fusion proteins were mixed with virus in fresh media and pre-incubated at $37^{\circ} \mathrm{C}$ for one hour. The Vero E6 cells were infected at a multiplicity of infection (MOI) of 0.06 with the neutralized virus solution at $37^{\circ} \mathrm{C}$ for one hour. Next, the neutralization mix was removed, culture medium was added, and cells were incubated at $37^{\circ} \mathrm{C}$ for 24 hours. Mock cells represent uninfected Vero E6 cells, incubated with culture medium. After 24 hours, cells were washed once with PBS and fixed with $4 \%$ paraformaldehyde (ChemCruz) at RT for $10 \mathrm{~min}$. Following a washing step with PBS, fixed Vero E6 cells were permeabilized with $0.5 \%$ saponin (Roth) in PBS at RT for 10 min to allow an in-cell ELISA. For this, cells were blocked with a mixture of $0.1 \%$ saponin and 10\% goat serum (Sigma) in PBS with gentle shaking at RT for one hour. Subsequently, Vero E6 cells were incubated with a 1:500 dilution of an anti-dsRNA J2 antibody (Jena Bioscience) in PBS supplemented with $1 \% \mathrm{FCS}$ at $4{ }^{\circ} \mathrm{C}$ overnight with shaking. Following four washing steps with wash 
buffer (PBS supplemented with 0.05\% Tween-20 (Roth)). Next, the plates were incubated with a 1:2,000 dilution of a goat anti-mouse IgG2a-HRP antibody (Southern Biotech) in PBS supplemented with $1 \%$ FCS and incubated with gently shaking at RT for one hour. Following four washing steps, 3,3',5,5'-

Tetramethylbenzidin (TMB) substrate (Invitrogen) was added to the wells and incubated in the dark for $10 \mathrm{~min}$. Colorimetric detection on a Tecan infinite F200 pro plate reader (Tecan) at $450 \mathrm{~nm}$ and at $560 \mathrm{~nm}$ was performed after stopping the color reaction by the addition of $2 \mathrm{~N} \mathrm{H}_{2} \mathrm{SO}_{4}$ (Roth).

Cell viability assay using SARS-CoV-2 variants of concern (VoC)

$24 \mathrm{~h}$ before infection, human lung epithelial A549 cells (ATCC-CCL-185), engineered to overexpress the ACE2 (A549-hACE2), were plated at 1.5E04 cells/well in a 96-well white well half area plate with clear bottom (Corning) in DMEM containing 2\% FCS, $1 \% \mathrm{P} / \mathrm{S}$ and $1 \%$ NEAA (all from Gibco) and incubated overnight at $37^{\circ} \mathrm{C}$ and $5 \% \mathrm{CO} 2$. A serial dilution of ACE2-IgG4-Fc construct 1 and 3 was performed and mixed with a defined volume of virus stocks of the indicated SARS-CoV-2 clinical isolates resulting in $80 \%$ cytotoxicity. After $1 \mathrm{~h}$ of pre-incubation at $37^{\circ} \mathrm{C}$, the neutralization mix of ACE2-IgG4-Fc construct and the respective SARS-CoV-2 isolates was added to A549-hACE2 cells. Virus-mediated killing of target cells was determined using a luminometric readout of virus-induced cytotoxicity. In brief, $72 \mathrm{~h}$ after infection cells were treated according to manufacturer's instructions: $15 \mu$ l CellTiter-Glo 2.0 reagent (Promega, Wisconsin, USA) were added to each well, incubated for $10 \mathrm{~min}$ in the dark at RT and luminescence was recorded ( 0.5 seconds integration time, no filter) using the Infinite F200 microplate reader (Tecan). Viability of cells and the corresponding infectious titer for each virus isolate was calculated by normalization of infected cells to untreated control cells (set to 100\%).

\section{Data Availability}

The authors declare that the data supporting the findings of this study are available within the article and its Supplementary Information files are available from the authors upon request. Source data are provided with this paper.

\section{Declarations}

\section{Competing interests}

A patent application has been filed by Formycon AG for the content disclosed in this study. The authors A.R., F.P. W., N.S., S.P., F.W., and C.B. are employees of Formycon AG. J.B. is advisory board member of Formycon AG.

\section{Author contributions:}

J.B., C.B. and U.P. developed the concept and designed the experiments. H.S., J.S., L.W., M.S., designed and performed experiments and analyzed the data. A.R. designed the constructs, supervised construct manufacturing and supervised physicochemical and functional analysis. C.-C.C, V.G. and O.T.K. provided 
critical reagents and methods. F.-P. W., N.S., S.P. and F.W. gave conceptual support and supervised experiments. H.S., J.S., A.R., F.-P. W., J.B. C.B. and U.P. wrote and revised the manuscript.

\section{Acknowledgements:}

The authors like to thank Polpharma Biologics Utrecht B.V. for performing the transient transfections and providing the fusion molecules. SARS-CoV-2 Spike S1 Inhibition ELISA was performed in collaboration with TebuBio, France. Binding to Fc receptors was performed in collaboration with Vela Laboratories, Austria. We are grateful to Volker Thiel, University of Bern, Switzerland, for providing the SARS-CoV-2-GFP, to Friedemann Weber, University of Giessen, Germany, for providing SARS-CoV (Frankfurt 1), and to Dr. Joachim J. Bugert, Institut für Mikrobiologie der Bundeswehr, for the B.1.1.7 variant.

The study was supported by grant AZ-1433-20 of the Bayerische Forschungsstiftung (Formycon AG, TUM) and AZ-1459-20C (O.T. Keppler), by the President's fund of the Helmholtz Association (CoViPa) and by the FOR-COVID network financed by the Ministry of Science and Arts (StMWK) of the State of Bavaria.

\section{References}

1. Hofmann, H. et al. Human coronavirus NL63 employs the severe acute respiratory syndrome coronavirus receptor for cellular entry. Proc Natl Acad Sci U S A 102, 7988-7993 (2005).

2. Hoffmann, M. et al. SARS-CoV-2 Cell Entry Depends on ACE2 and TMPRSS2 and Is Blocked by a Clinically Proven Protease Inhibitor. Cell 181, 271-280 e278 (2020).

3. Wrapp, D. et al. Cryo-EM structure of the 2019-nCoV spike in the prefusion conformation. Science 367, 1260-1263 (2020).

4. Cantuti-Castelvetri, L. et al. Neuropilin-1 facilitates SARS-CoV-2 cell entry and infectivity. Science, eabd2985 (2020).

5. Crackower, M.A. et al. Angiotensin-converting enzyme 2 is an essential regulator of heart function. Nature 417, 822-828 (2002).

6. Ding, Y. et al. Organ distribution of severe acute respiratory syndrome (SARS) associated coronavirus (SARS-CoV) in SARS patients: implications for pathogenesis and virus transmission pathways. $J$ Patho/ 203, 622-630 (2004).

7. Hamming, l. et al. Tissue distribution of ACE2 protein, the functional receptor for SARS coronavirus. A first step in understanding SARS pathogenesis. J Pathol 203, 631-637 (2004).

8. Jiang, F. et al. Angiotensin-converting enzyme 2 and angiotensin 1-7: novel therapeutic targets. Nat Rev Cardiol 11, 413-426 (2014).

9. Donoghue, M. et al. A novel angiotensin-converting enzyme-related carboxypeptidase (ACE2) converts angiotensin I to angiotensin 1-9. Circ Res 87, E1-9 (2000).

10. Tipnis, S.R. et al. A human homolog of angiotensin-converting enzyme. Cloning and functional expression as a captopril-insensitive carboxypeptidase. J Biol Chem 275, 33238-33243 (2000). 
11. Lu, H., Cassis, L.A., Kooi, C.W. \& Daugherty, A. Structure and functions of angiotensinogen. Hypertens Res 39, 492-500 (2016).

12. Santos, R.A.S. et al. The ACE2/Angiotensin-(1-7)/MAS Axis of the Renin-Angiotensin System: Focus on Angiotensin-(1-7). Physiol Rev 98, 505-553 (2018).

13. Burrell, L.M., Johnston, C.I., Tikellis, C. \& Cooper, M.E. ACE2, a new regulator of the renin-angiotensin system. Trends Endocrinol Metab 15, 166-169 (2004).

14. Liu, M.Y., Zheng, B., Zhang, Y. \& Li, J.P. Role and mechanism of angiotensin-converting enzyme 2 in acute lung injury in coronavirus disease 2019. Chronic Dis Transl Med 6, 98-105 (2020).

15. Wu, J., Deng, W., Li, S. \& Yang, X. Advances in research on ACE2 as a receptor for 2019-nCoV. Cell Mol Life Sci (2020).

16. Kruse, R.L. Therapeutic strategies in an outbreak scenario to treat the novel coronavirus originating in Wuhan, China. F1000Res 9, 72 (2020).

17. Batlle, D., Wysocki, J. \& Satchell, K. Soluble angiotensin-converting enzyme 2: a potential approach for coronavirus infection therapy? Clin Sci (Lond) 134, 543-545 (2020).

18. Haschke, M. et al. Pharmacokinetics and pharmacodynamics of recombinant human angiotensinconverting enzyme 2 in healthy human subjects. Clin Pharmacokinet 52, 783-792 (2013).

19. Khan, A. et al. A pilot clinical trial of recombinant human angiotensin-converting enzyme 2 in acute respiratory distress syndrome. Crit Care 21, 234 (2017).

20. Zoufaly, A. et al. Human recombinant soluble ACE2 in severe COVID-19. The Lancet Respiratory Medicine (2020).

21. Liu, P., Xie, X., Gao, L. \& Jin, J. Designed variants of ACE2-Fc that decouple anti-SARS-CoV-2 activities from unwanted cardiovascular effects. Int J Biol Macromol 165, 1626-1633 (2020).

22. Iwanaga, N. et al. Novel ACE2-IgG1 fusions with improved activity against SARS-CoV2. bioRxiv, 2020.2006.2015.152157 (2020).

23. Huang, K.Y. et al. Humanized COVID-19 decoy antibody effectively blocks viral entry and prevents SARS-CoV-2 infection. EMBO Mol Med n/a, e12828 (2020).

24. Lui, I. et al. Trimeric SARS-CoV-2 Spike interacts with dimeric ACE2 with limited intra-Spike avidity. bioRxiv, 2020.2005.2021.109157 (2020).

25. Lei, C. et al. Neutralization of SARS-CoV-2 spike pseudotyped virus by recombinant ACE2-Ig. Nat Commun 11, 2070 (2020).

26. Glasgow, A. et al. Engineered ACE2 receptor traps potently neutralize SARS-CoV-2. Proc Natl Acad Sci USA (2020).

27. Hengenix Biotech Inc. (2020).

28. Bournazos, S., Gupta, A. \& Ravetch, J.V. The role of IgG Fc receptors in antibody-dependent enhancement. Nat Rev Immunol 20, 633-643 (2020).

29. Jafarzadeh, A., Chauhan, P., Saha, B., Jafarzadeh, S. \& Nemati, M. Contribution of monocytes and macrophages to the local tissue inflammation and cytokine storm in COVID-19: Lessons from SARS 
and MERS, and potential therapeutic interventions. Life Sci 257, 118102 (2020).

30. Manickam, C., Sugawara, S. \& Reeves, R.K. Friends or foes? The knowns and unknowns of natural killer cell biology in COVID-19 and other coronaviruses in July 2020. PLoS Pathog 16, e1008820 (2020).

31. de Taeye, S.W. et al. FcgammaR Binding and ADCC Activity of Human IgG Allotypes. Front Immunol 11,740 (2020).

32. Correia, I.R. Stability of IgG isotypes in serum. MAbs 2, 221-232 (2010).

33. Aalberse, R.C. \& Schuurman, J. IgG4 breaking the rules. Immunology 105, 9-19 (2002).

34. Dumet, C., Pottier, J., Gouilleux-Gruart, V. \& Watier, H. Insights into the IgG heavy chain engineering patent landscape as applied to IgG4 antibody development. MAbs 11, 1341-1350 (2019).

35. Handlogten, M.W. et al. Prevention of Fab-arm exchange and antibody reduction via stabilization of the IgG4 hinge region. MAbs 12, 1779974 (2020).

36. Yan, R. et al. Structural basis for the recognition of SARS-CoV-2 by full-length human ACE2. Science 367, 1444-1448 (2020).

37. Lan, J. et al. Structure of the SARS-CoV-2 spike receptor-binding domain bound to the ACE2 receptor. Nature 581, 215-220 (2020).

38. Scapin, G. et al. Structure of full-length human anti-PD1 therapeutic IgG4 antibody pembrolizumab. Nat Struct Mol Biol 22, 953-958 (2015).

39. Thi Nhu Thao, T. et al. Rapid reconstruction of SARS-CoV-2 using a synthetic genomics platform. Nature 582, 561-565 (2020).

40. Drosten, $\mathrm{C}$. et al. Identification of a novel coronavirus in patients with severe acute respiratory syndrome. N Engl J Med 348, 1967-1976 (2003).

41. Bohmer, M.M. et al. Investigation of a COVID-19 outbreak in Germany resulting from a single travelassociated primary case: a case series. Lancet Infect Dis 20, 920-928 (2020).

42. Rothe, C. et al. Transmission of 2019-nCoV Infection from an Asymptomatic Contact in Germany. N Engl J Med 382, 970-971 (2020).

43. Wolf, G.K. et al. Clinical and Epidemiological Features of a Family Cluster of Symptomatic and Asymptomatic Severe Acute Respiratory Syndrome Coronavirus 2 Infection. J Pediatric Infect Dis Soc 9, 362-365 (2020).

44. Hu, J. et al. Emerging SARS-CoV-2 variants reduce neutralization sensitivity to convalescent sera and monoclonal antibodies. Cellular \& Molecular Immunology 18, 1061-1063 (2021).

45. Wang, P. et al. Antibody resistance of SARS-CoV-2 variants B.1.351 and B.1.1.7. Nature (2021).

46. Administration, U.F.a.D. Development of Monoclonal Antibody Products Targeting SARSCoV-2, Including Addressing the Impact of Emerging Variants, During the COVID-19 Public Health Emergency. Guideline for Industry (2021).

47. Wysocki, J. et al. Targeting the degradation of angiotensin II with recombinant angiotensinconverting enzyme 2: prevention of angiotensin II-dependent hypertension. Hypertension 55, 90-98 
(2010).

48. Tikellis, C. \& Thomas, M.C. Angiotensin-Converting Enzyme 2 (ACE2) Is a Key Modulator of the Renin Angiotensin System in Health and Disease. Int J Pept 2012, 256294 (2012).

49. Liu, P. et al. Novel ACE2-Fc chimeric fusion provides long-lasting hypertension control and organ protection in mouse models of systemic renin angiotensin system activation. Kidney Int 94, 114-125 (2018).

50. Bernardi, A. et al. Development and simulation of fully glycosylated molecular models of ACE2-FC fusion proteins and their interaction with the SARS-CoV-2 spike protein binding domain. PLoS One 15, e0237295 (2020).

51. Sockolosky, J.T. \& Szoka, F.C. The neonatal Fc receptor, FcRn, as a target for drug delivery and therapy. Adv Drug Deliv Rev 91, 109-124 (2015).

52. Latvala, S., Jacobsen, B., Otteneder, M.B., Herrmann, A. \& Kronenberg, S. Distribution of FcRn Across Species and Tissues. J Histochem Cytochem 65, 321-333 (2017).

53. Tzaban, S. et al. The recycling and transcytotic pathways for IgG transport by FcRn are distinct and display an inherent polarity. J Cell Biol 185, 673-684 (2009).

54. Muhammed, Y. Best IgG Subclass for the Development of Therapeutics Monoclonal Antibodies Drugs and their Commercial Production: A Review. Immunome Res 16 (2020).

55. Chakraborty, S. et al. Proinflammatory IgG Fc structures in patients with severe COVID-19. Nat Immunol (2020).

56. Khan, M.I. et al. Comparative genome analysis of novel coronavirus (SARS-CoV-2) from different geographical locations and the effect of mutations on major target proteins: An in silico insight. PLoS One 15, e0238344 (2020).

57. Islam, M.R. et al. Genome-wide analysis of SARS-CoV-2 virus strains circulating worldwide implicates heterogeneity. Sci Rep 10, 14004 (2020).

58. Mercatelli, D. \& Giorgi, F.M. Geographic and Genomic Distribution of SARS-CoV-2 Mutations. Front Microbio/ 11, 1800 (2020).

59. Korber, B. et al. Tracking Changes in SARS-CoV-2 Spike: Evidence that D614G Increases Infectivity of the COVID-19 Virus. Cell 182, 812-827 e819 (2020).

60. Fernandez, A. Structural Impact of Mutation D614G in SARS-CoV-2 Spike Protein: Enhanced Infectivity and Therapeutic Opportunity. ACS Med Chem Lett 11, 1667-1670 (2020).

61. Santos, J.C. \& Passos, G.A. The high infectivity of SARS-CoV-2 B.1.1.7 is associated with increased interaction force between Spike-ACE2 caused by the viral N501Y mutation. bioRxiv, 2020.2012.2029.424708 (2021).

62. Mallapaty, S. COVID mink analysis shows mutations are not dangerous - yet. Nature 587, 340-341 (2020).

63. Oude Munnink, B.B. et al. Transmission of SARS-CoV-2 on mink farms between humans and mink and back to humans. Science, eabe5901 (2020). 
64. Garcia-Beltran, W.F. et al. COVID-19-neutralizing antibodies predict disease severity and survival. Cell 184, 476-488 e411 (2021).

65. Moore, M.J. et al. Retroviruses pseudotyped with the severe acute respiratory syndrome coronavirus spike protein efficiently infect cells expressing angiotensin-converting enzyme 2 . Journal of virology 78, 10628-10635 (2004).

66. Walls, A.C. et al. Structure, Function, and Antigenicity of the SARS-CoV-2 Spike Glycoprotein. Cell 181, 281-292 e286 (2020).

67. Lehr, B., Robinson, J., Burdick, R. \& Tholudur, A. Evaluation of a Variable-Pathlength Spectrophotometer: A Comparable Instrument for Determining Protein Concentration. BioProcess International 13, 46-51 (2015).

68. Wolfel, R. et al. Virological assessment of hospitalized patients with COVID-2019. Nature 581, 465469 (2020).

69. Baer, A. \& Kehn-Hall, K. Viral concentration determination through plaque assays: using traditional and novel overlay systems. J Vis Exp, e52065 (2014).

\section{Figures}


a

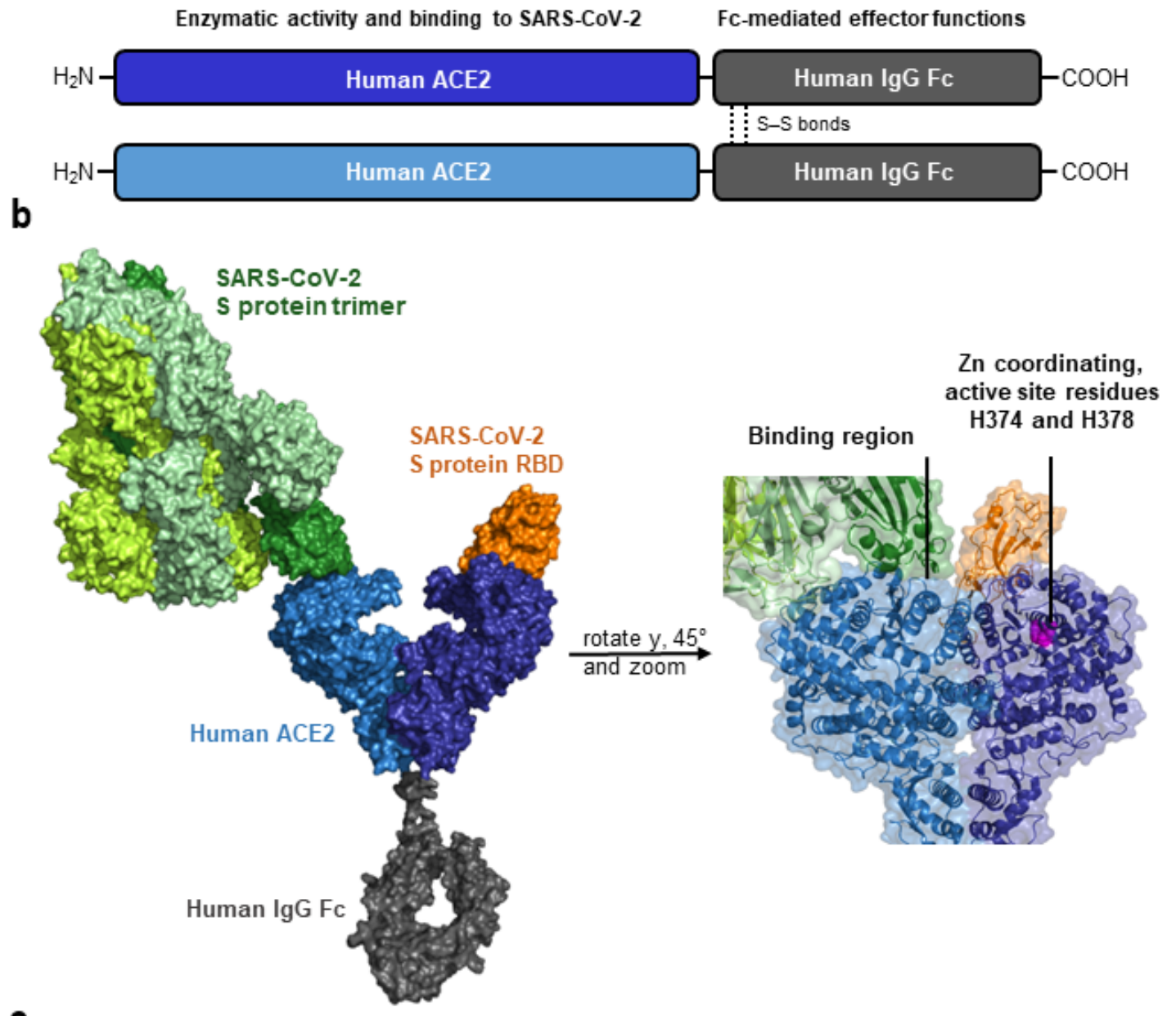

\begin{tabular}{|c|c|c|}
\hline Construct & $\begin{array}{c}\text { ACE2 sequence } \\
\text { (active site mutation) }\end{array}$ & $\begin{array}{c}\text { IgG isotype } \\
\text { (hinge region modification) }\end{array}$ \\
\hline 1 & Q18-G732 (no) & $\operatorname{lgG} 4$ (S228P) \\
\hline 2 & Q18-S740 (no) & $\operatorname{lgG} 4$ (S228P) \\
\hline 3 & Q18-G732 (H374N, H378N) & $\operatorname{lgG} 4$ (S228P) \\
\hline 4 & Q18-S740 (H374N, H378N) & $\operatorname{lgG} 4$ (S228P) \\
\hline 5 & Q18-G732 (no) & $\operatorname{lgG} 1$ (truncated) \\
\hline 6 & Q18-S740 (no) & $\operatorname{lgG} 1$ (truncated) \\
\hline 7 & Q18-G732 (H374N, H378N) & $\operatorname{lgG} 1$ (truncated) \\
\hline 8 & Q18-S740 (H374N, H378N) & $\operatorname{lgG} 1$ (truncated) \\
\hline
\end{tabular}

\section{Figure 1}

Structural elements in the ACE2-Fc constructs. a Schematic depiction of the main parts in an engineered ACE2-Fc molecule and their functional properties. b Design of the ACE2-Fc fusion protein; ACE2 parts in light and dark blue, IgG-Fc part in gray, spike (S) protein trimer in green and the receptor-binding domain (RBD) located at the tip of each spike protein in orange and dark green. The binding region as well as active site residues $\mathrm{H} 374$ and $\mathrm{H} 378$ important for the enzymatic activity of ACE2 are highlighted. 
Structures of the following Protein Data Bank (PBD) identifiers were used for modeling: $6 \mathrm{M} 17,6 \mathrm{M} 0 \mathrm{~J}$, $6 \mathrm{VSB}, 5 \mathrm{DK} 3$. c Nomenclature and structural variations in the ACE2-Fc constructs.


b


Figure 2

Structural and functional characteristics of the ACE2-Fc proteins. a Far-UV CD spectra (left) and Near-UV $\mathrm{CD}$ spectra (right) of ACE2-Fc constructs indicating that all proteins exhibit similar secondary and tertiary structures. b Chromatograms and molecular mass from size-exclusion chromatography coupled to multi- 
angle light scattering (SEC-MALS) indicating that the ACE2-Fc molecules form homodimers. c Nonreducing (top) and reducing (bottom) sodium dodecyl sulfate polyacrylamide gel electrophoresis (SDSPAGE) analysis showing that intermolecular disulfide bonds in the homodimers are formed. $d$ Comparison of fluorescence signals over time obtained in an assay testing the cleavage of a fluorescent peptidyl-4-methylcoumaryl-7-amide (MCA). Relative fluorescent units (RFU) are given. e Amount of MCA cleaved after 30 min of incubation with the ACE2-Fc constructs. Ref1 and Ref2 are two different commercially available ACE2-Fc proteins from Genscript and Acrobiosystems, respectively. Bars are mean values; error bars depict the $95 \%$ confidence interval of six independent experiments shown as circles.
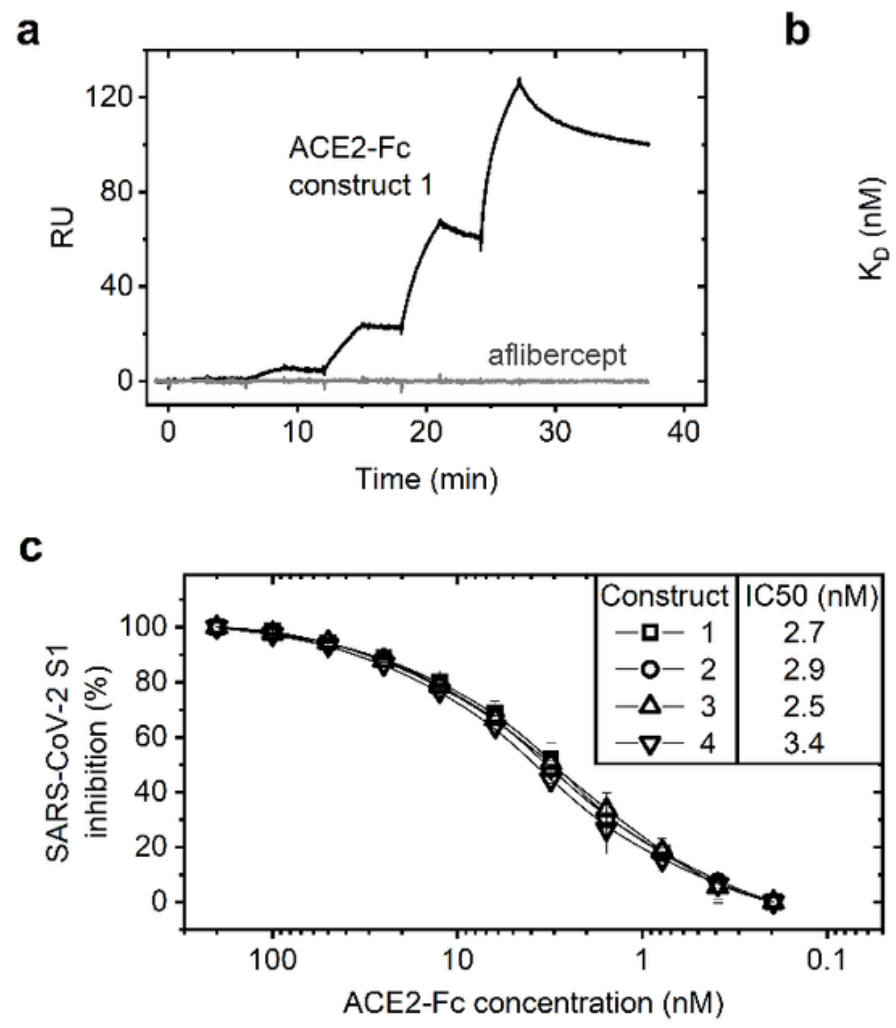

b

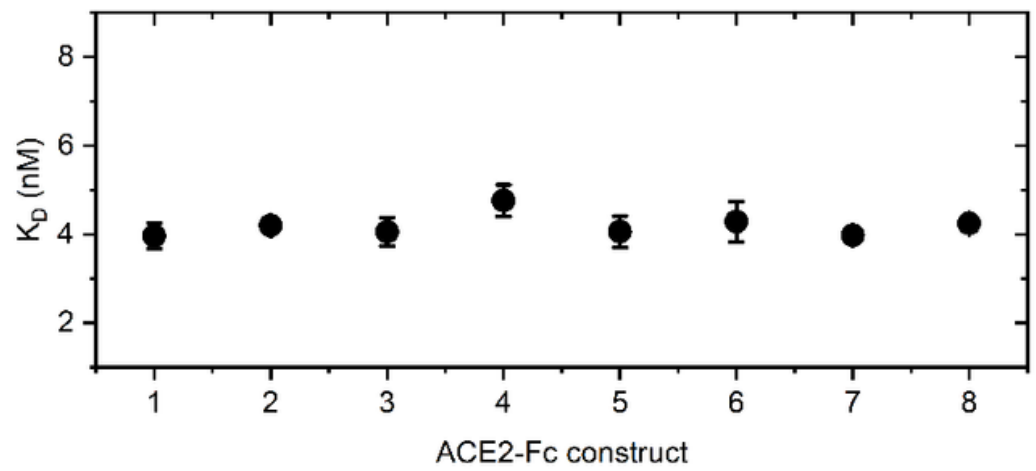

\section{Figure 3}

Interaction of the ACE2-Fc constructs with the SARS-CoV-2 RBD. a Surface plasmon resonance (SPR) was performed to obtain binding curves of ACE2-Fc fusion constructs and an unrelated Fc fusion protein (aflibercept) to an immobilized RBD from SARS-CoV-2. An exemplary binding curve is shown (RU = Response Units). $b$ Binding constants of the ACE2-Fc constructs towards the RBD of SARS-CoV-2 (Mean $\pm S D$ of triplicate measurements). c ACE2-Fc fusion proteins were pre-incubated with the SARS-CoV-2 spike S1 protein and tested in a competition ELISA for their ability to neutralize S1 binding to immobilized ACE2 protein. Potent inhibition of SARS-CoV-2 spike S1 protein by ACE2-IgG4-Fc constructs (left) and ACE2-IgG1-Fc constructs (right). Data are represented as means \pm SD of at least two independent experiments. 


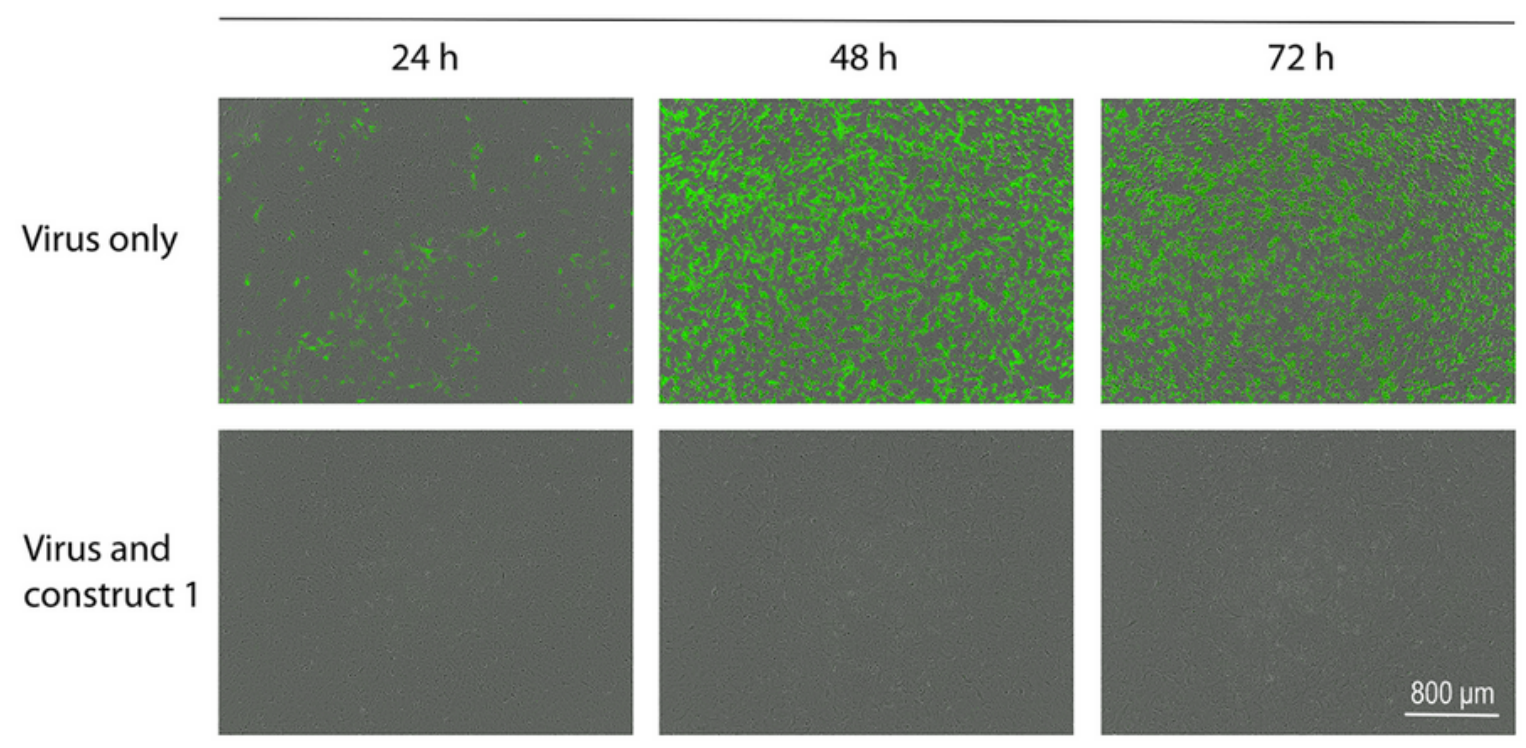

b

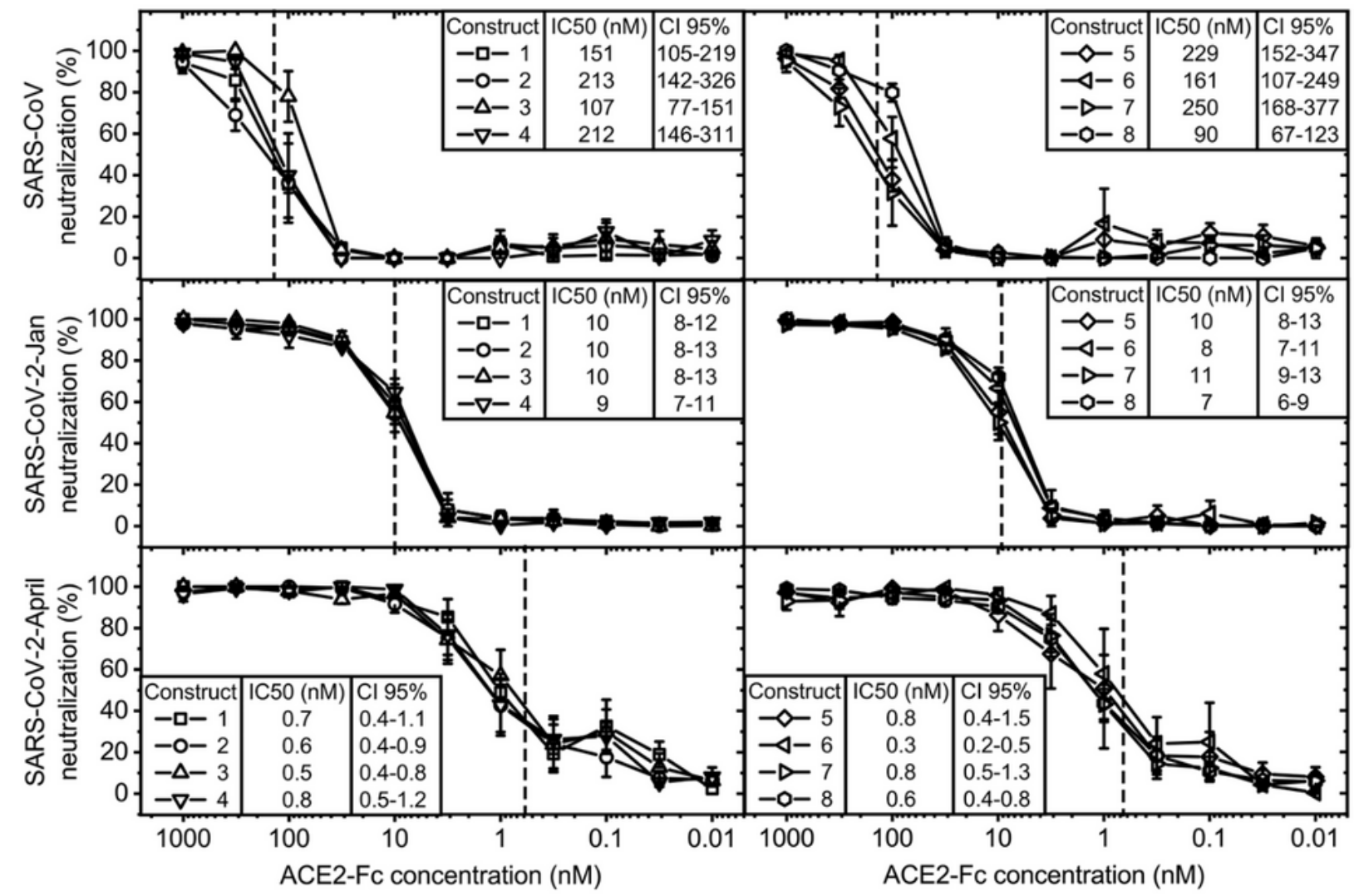

Figure 4

Effect of ACE2-Fc on SARS-CoV-2-GFP infection and inhibition of SARS-CoV-2 primary isolates. a ACE2IgG4-Fc reduces SARS-CoV-2-GFP replication. Representative fluorescent images of Vero E6 cells infected with SARS-CoV-2-GFP (multiplicity of infection (MOI) = 0.6) pre-incubated with ACE2-IgG4-Fc fusion construct 1 (632 nM). b ACE2-Fc fusion proteins potently neutralize coronaviruses. Serial dilutions of ACE2-Fc fusion proteins were pre-incubated with different coronaviruses and tested for their ability to 
neutralize the virus before infection of Vero E6 cells. Neutralization of SARS-CoV (top), SARS-CoV-2-Jan (middle) and SARS-CoV-2-April (bottom) by ACE2-IgG4-Fc constructs (left) and ACE2-IgG1-Fc constructs (right) is shown. Data given are means \pm SEM of three independent experiments each. $50 \%$ inhibitory concentrations (IC50) determined as well as the 95\% confidence interval (CI 95\%) are given for each construct. The dashed lines indicate the IC50 values on the corresponding curves.

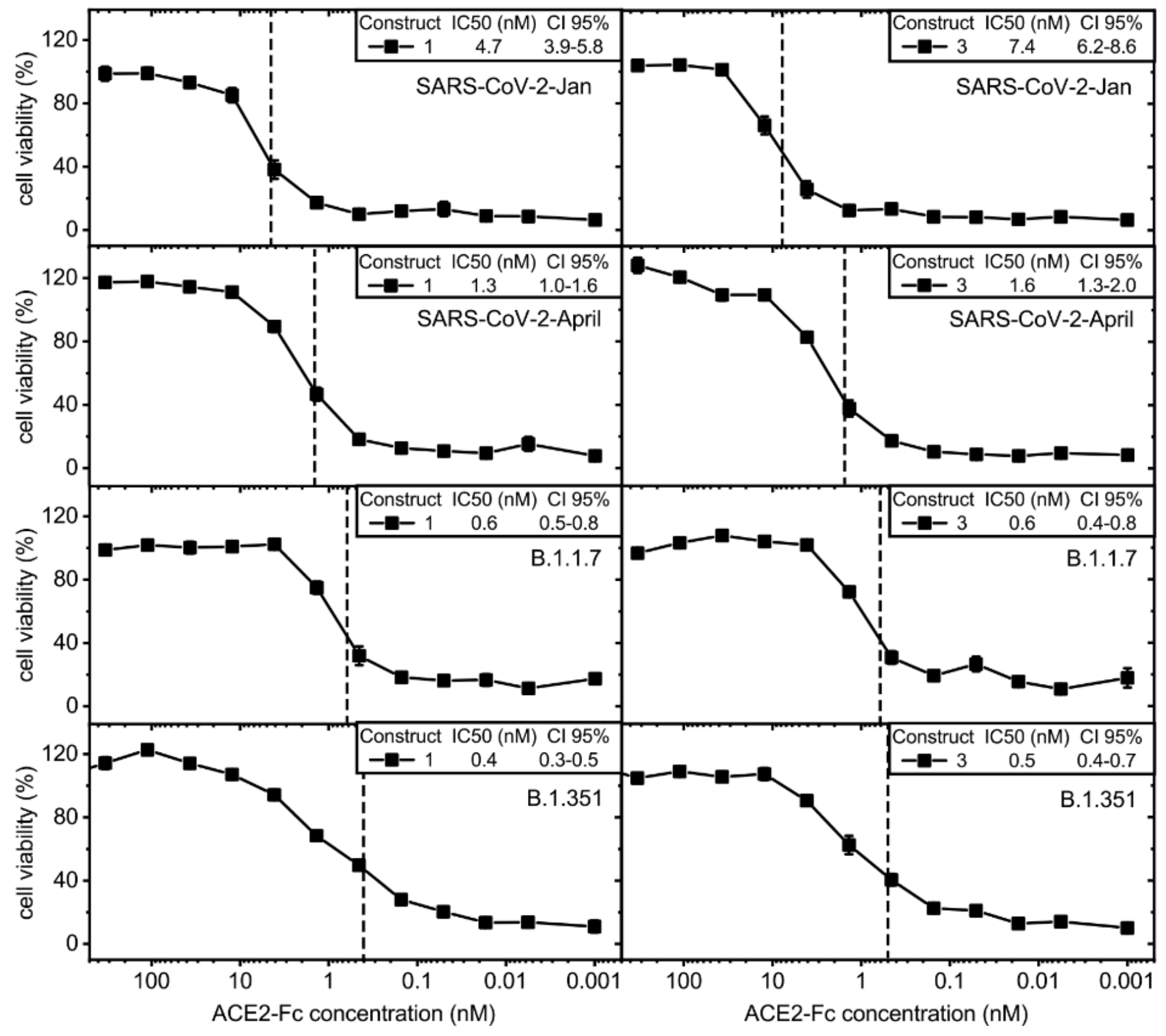

Figure 5

Neutralization potency of ACE2-IgG4-Fc fusion proteins increases with evolution of pandemic SARS-CoV2 variants. Serial dilutions of ACE2-IgG4-Fc fusion constructs 1 and 3 were pre-incubated with the indicated SARS-CoV-2 primary isolates or VoCs and tested for their ability to prevent cytotoxicity following infection of A549-hACE2 cells. Neutralization of SARS-CoV-2-Jan, SARS-CoV-2-April and SARSCoV-2 VoCs B.1.1.7 and B.1.351 by enzymatically active ACE2-IgG4-Fc construct 1 (left) and 
enzymatically inactive ACE2-IgG4-Fc construct 3 (right). Data given are means \pm SEM of three independent experiments each. 50\% inhibitory concentrations (IC50 values) determined as well as the 95\% confidence interval ( $\mathrm{Cl}$ 95\%) are shown for each construct. The dashed lines indicate the IC50 values on the corresponding curves.

\section{Supplementary Files}

This is a list of supplementary files associated with this preprint. Click to download.

- Supplementarydata.docx 